\title{
A SMART STICK WITH KEYPAD FOR DUAL SENSORY IMPAIRED
}

\author{
L. MARY ANGELIN PRIYA ${ }^{1} \&$ REJI SIVANTHAN ${ }^{2}$ \\ ${ }^{1}$ Assistant Professor, Department of Electrical and Electronics Engineering, \\ Rajalakshmi Institute of Technology, Chennai, India \\ ${ }^{2} X R$ Developer, Aatral Creations LLP, Chennai, India
}

\begin{abstract}
In today's modern world many technologies has been implemented for blind, deaf and dumb separately. No new technology has been implemented for the people with dual sensory impaired (all three). In this paper a new method has been implemented where the features needed by these dual sensory impaired for communication, emergency alert and obstacle detection comes under a single stick with foldable one. By using this stick the dual sensory impaired people can able to travel anywhere which will widen their view with the society

KEYWORDS: Arduino Mega, Ultrasonic Sensor, Vibration Motor, Servo Motor, LDR, Guesture Sensor
\end{abstract}

Received: Jun 08, 2020; Accepted: Jun 28, 2020; Published: Aug 17, 2020; Paper Id.: IJMPERDJUN2020779

\section{INTRODUCTION}

Obstacle detection and communication are two major factors that are to be considered when designing a product that aims to aid the people who are sensory deprived at the same time. Such people make use of their hands and tools such as white canes for obstacle detection. Hand gestures and language slikebraille are used as a mean for communication. People, while using white cane, perceive the presence of nearby obstacles by touch sense through the impact created by the cane on the obstacle in its path. This technique, though perfected to its limits by the people wielding it, is still limited when we consider the possibilities of perception that can be obtained through a hand held device. Hence, this project plans to enhance the cane through obstacle detection module and braille keypad.

The recognition of the surrounding is obtained with the help of an obstacle detection module that is placed near the bottom of the sticksor. This allows the module to operate within its max range of $15^{\circ}$ angle with respect to the vertical direction. However, this range is insufficient for the obstacle detection along the horizontal direction. Hence, this obstacle detection module is mounted on a 360 degree ranger rotation that is capable of swinging the obstacle detection module horizontally.

In the literature, different techniques have been proposed for sticksor. In $[1,10]$, proposed an idea of designing electronic stick using Global System Messaging (GSM), Global Positioning System (GPS) and Ultrasonic technology. In [2,4,6,7], the system uses six dot vibrators to display characters and System having Braille pad for writing the Braille letters. SMS facility used for communication.[3], merging data provided by the two sensor types to allow more accurate information, to be transmitted to the user via a

Bluetooth module as a voice message specifying the object nature, characteristics and the distance between the detected obstacles. In [5], multiple sensors are used to detect obstacles. [8] a device control section which will 
be operated by using Braille touch keypad, the device control section of a microcontroller connected with the load devices. The AC devices can be controlled to the controller through a relay.

In [9], proposed the implementation of braille to word and audio converter as output using FPGA.[11-12], are liable solution encompassing of a cane and a shoe that could communicate with the users through voice alert and prerecorded messages. [13], new technique and communications method for blind persons. Conversion of English language to braille and it was detected by Six vibration motors that are placed in the glove.[14], the user pushes the lightweight GuideCane forward and When the GuideCane's ultrasonic sensors detect an obstacle, the embedded computer determines a suitable direction of motion that steers the GuideCane and the user around it [15] focuse donanavigation system called Virtual Leading Blocks for the Deaf-Blind, it consists of a wearable interface for finger braille. It uses two Linux-based wrist watch computers as a hybrid interface for verbal and non-verbal communication in order to inform users of their direction and position through the tactile sensation.

\section{THEORETICAL BACKGROUND}

\section{Stick and Keypad Specification}

This product is mainly built around a walking stick of robust aluminum construction with foldable one. The length of the stick is $92 \mathrm{~cm}$ and thickness is $18 \mathrm{~cm}$. The keypad is designed to be a handheld device of dimensions $\mathbf{1 0 0 m m} * \mathbf{5 0 m m} * \mathbf{1 5 m m}$. Buttons are spaced with $\mathbf{1 0} \mathbf{~ m m}$ gap to provide an ergonomic handle

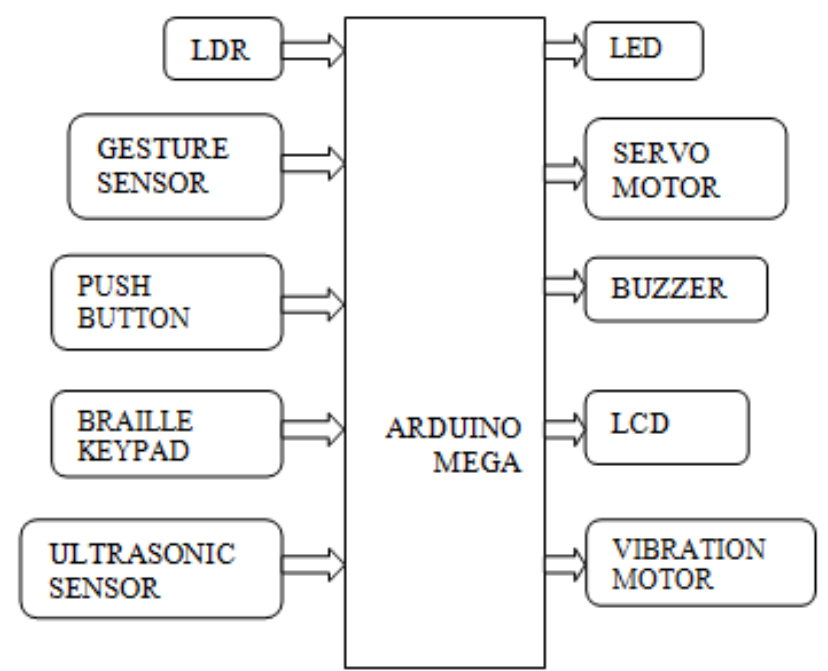

Figure 1: Block Diagram for Dual Sensory Impaired.

\section{DESIGN METHODOLOGY}

The sticksor mainly consists of the following modules:

- Obstacledetection

- Extending the range ofdetection

- Emergency alert

- Night alert forsociety

- Communication 


\section{Obstacle Detection}

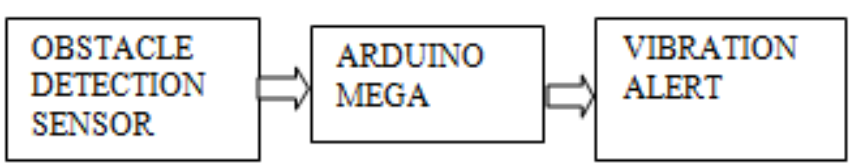

Figure 2: Block Diagram for Obstacle Detection.

To detect the obstacles obstacle detection sensor is used. The sensor will emit the sound waves and detect the obstacle or object and bounce backward to the sensor. The input from obstacle detection sensor will be provided to processor where it performs the distance calculation. If the calculated range is below $400 \mathrm{~cm}$ it provides a vibration alert to the user. The obstacle detection sensor has to detect the obstacle within the range of $400 \mathrm{~cm}$. The obstacle detection sensor will have transmitter and receiver pin. To initialize the transmitter pin it will send a pulse of minimal timer period of ten micro second delay. Within that delay it will send eight sonic burst of data at $40 \mathrm{KHz}$. The sound wave will detect the obstacles. When it detects, the receiver pin will be high and the timer will start and when the wave bounces back from the obstacle and reaches the sensor, receiver pin will go low and the timer will be stopped. The processor will get the timer value from timer register and calculate the distance.

\section{Procedural Calculation}

Distance $=($ speed $*$ time $) / 2$

$\mathrm{S}=$ speed of sound $=344 \mathrm{~m} / \mathrm{s}$

$\mathrm{T}=$ time calculate the to and fro distance

Speed of the sound $=340 \mathrm{~m} / \mathrm{s}$

$$
=0.034 \mathrm{~cm} / \mathrm{us}
$$

Time $=271 \mathrm{us}=271 \mathrm{us} * 0.034 \mathrm{~cm} / \mathrm{us}=9.214 / 2$

$$
=4.607 \mathrm{~cm}
$$

To display the value in centimeter it should be divided by 59. The timer value loaded in the timer register is 380000 microsecond. The received value from the timer register will be calculated using the above formula. Once the range is detected if the range is below $400 \mathrm{~cm}$ the vibration motor will provide a vibration alert to the user.

\section{COMMUNICATION}

The dual sensory impaired people will find difficult to communicate with normal people because the language used for communication will be different for both of them. By using this keypad they can communicate easily with normal people because it converts the braille language into text which is understood by normal people.

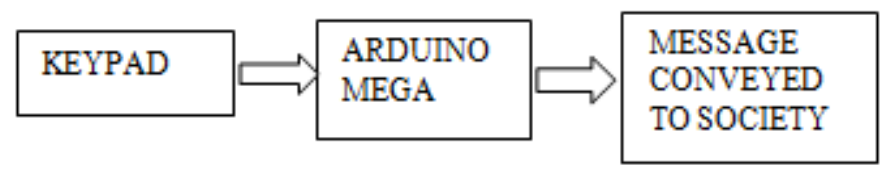

Figure 3: Block Diagram for Communication. 


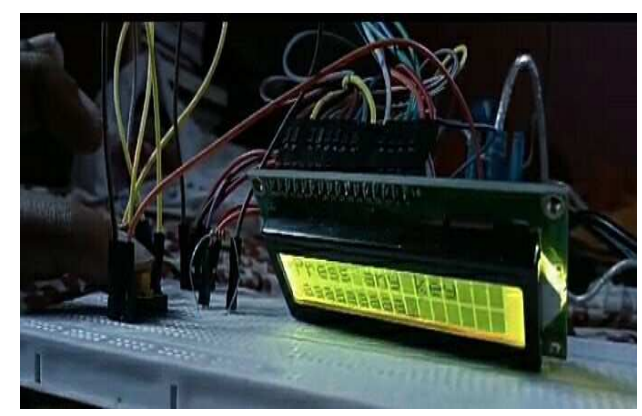

Figure 4: Hardware Result for Braille Keypad.

The input of Braille language is given to the processor by keypad. The input from this keypad is communicated to the society with the help of an LCD display. The keypad consists of six buttons. The micro controller will convert the braille input to text format.The Braille keypad functions based on the concept that all the buttons pressed before complete release of those buttons together constitute the input given by the user. Thus the program consists of two major functions Wait For Release and Read Keys.

\section{Steps to Display a Character c}

Set $\mathrm{x}=0$. When a button, is pressed $\mathrm{x}$ becomes 1 . Left shift the $\mathrm{x}$ values 5 times (based on the number given in binary digit arrangements).Perform OR operation $\mathrm{a} \mid \mathrm{x}$ and store the value in a

$$
\begin{aligned}
& x=100000 \text { (left shift) } \\
& a=000000 \\
& a=100000
\end{aligned}
$$

Then check if any other buttons are pressed. Button 4 is pressed. Corresponding binary digit 2.Left shift $\mathrm{x}$ value 2 times and

$$
\begin{aligned}
& x=100 \\
& a=100000
\end{aligned}
$$

100100

Then again check if buttons are pressed. If not display the character. The character for the buttons pressed is C.

\section{To Display a Number 1}

Same process is carried out as character. Before entering a number \# symbol has to be pressed. After the button 5 is pressed it will generate the a value and perform ascii conversion a binary digit value will be 100000 . Generate the ascii value for binary number 100000 .The ascii value for a is 97 . To convert the character in to number

$$
\mathrm{c}=\mathrm{c}-48
$$

c value is 97

$$
\mathrm{C}=97-48=49
$$

The corresponding ascii value for character a is 1 , therefore the number 1 will be displayed. 


\section{ROTATION OF ULTRASONIC SENSOR WITH SERVO MOTOR}

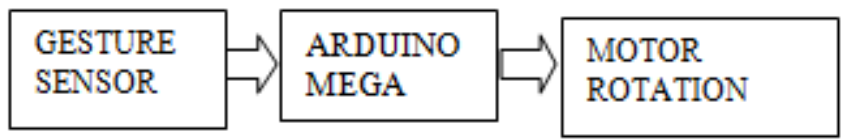

Figure 5: Block Diagram for Servo Motor Rotation.

To detect the movement of hands gesture sensor is used. The gesture sensor will detect to which direction the hand is moved and provide the direction to the processor. Based on the input provided by gesture sensor, the processor will make the 180 degree ranger rotation to rotate in the specified degree. The communication between the gesture sensor and processor is done through I2C.

\section{Emergency Alert}

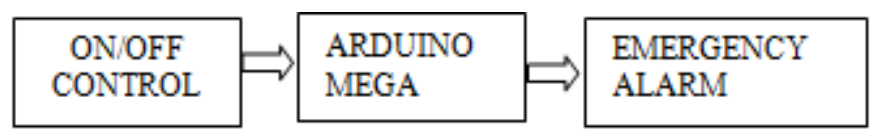

Figure 6: Block Diagram for Emergency Alert.

When the dual sensory impaired people is in danger or they lost in some places, they will need the help of others. Therefore to alert the near by people this module is used. In emergency situation when the on/off control is pressed a signal will be send to the processor. The processor will process the signal and send the output signal to the emergency alarm pin. A continuous sound will be produced untilit receives the next signal from processor.

\section{LED LIGHT FOR NIGHT ALERT}

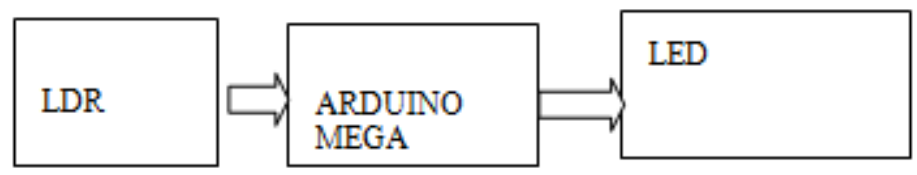

Figure 7: Block Diagram for Night Alert.

The LED light is used to alert society. Three white LED's are placed in the top, middle and bottom of the stick. When the intensity of the light increases the resistance of LDR decreases so the LED will not glow. When the intensity of light decreases then the resistance will increase so which in turn LED will glow.

\section{RESULT}

The hardware experimental setup is shown below how the proposed work of the project of a smart sticksor for dual sensory impaired is implemented in Arduino Mega 


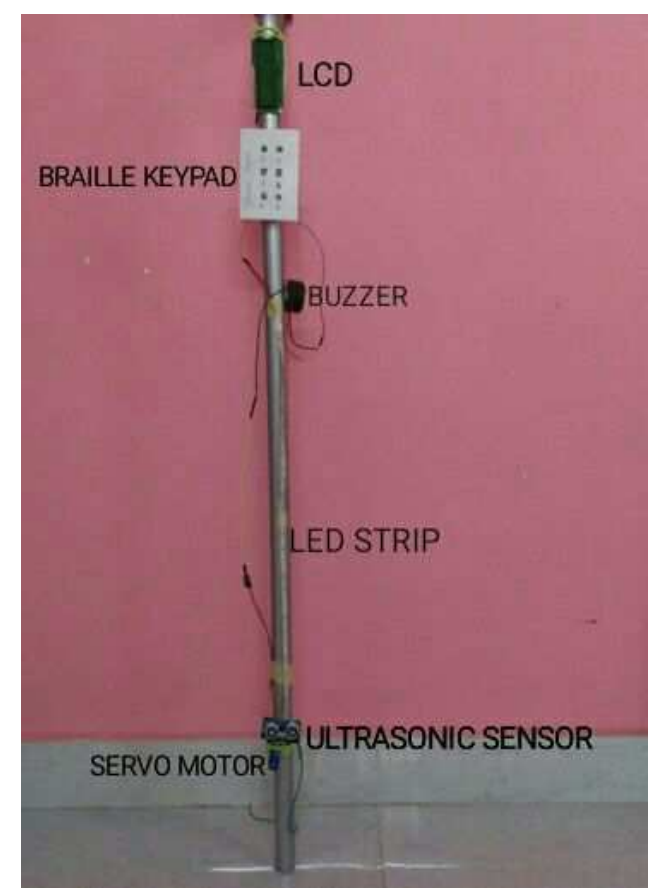

Figure 8: Experimental Setup of Smart Stick.

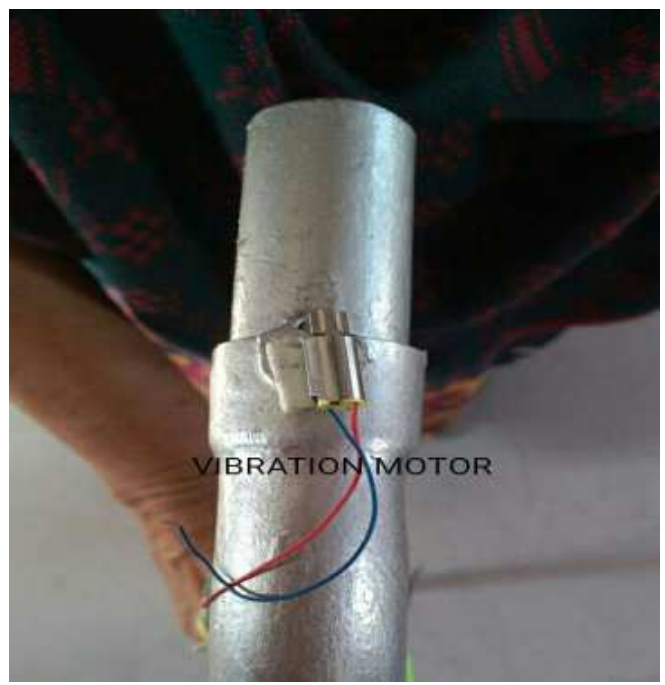

Figure 9: Experimental Setup of Smart Stick Topview.

\section{CONCLUSIONS}

Thus the hardware for dual sensory impaired people is done using arduinomega. Both the smart skicksor and braille keypad has been integrated as one device with additional features added. This project will help the dual sensory impaired people to avoid obstacles and communicate better

\section{REFERENCES}

1. Gurubaran and K. Gowrishankar, "A Survey of Voice Aided Electronic Stick for Visually Impaired People," International Journal of Innovative Research in Advanced Engineering (IJIRAE), vol. 1, no. 8, pp. 342-346, September(2014).

2. M.Varsha and R.M.Khaire, "Hardware-Based Braille Note Taker," International Journal of Science, Engineering and Technology Research (IJSETR), vol. 4, no. 11, pp. 3957-3959, November 2015. 
3. A. G.Gaikwad and H. K. Waghmare, "Ultrasonic Smart Cane Indicating A Safe Free Path To Blind People," International Journal Of Advanced Computing And Electronics Technology (Ijacet), vol. 2, no. 4, pp. 12-17, 2015.

4. Anandh, S., R. Raja, and J. Jaya Prakash. "Efficacy of Seated Balance Exercises with Sensory Feedback on Balanced Sitting among Hemorrhagic Stroke Patients. "TJPRC: International Journal of Physiotherapy \& Occupational Therapy (TJPRC: IJPOT) 3. 2, Dec 2017, 1-8

5. Zope.P. H. and H. Dahake, "Design and Implementation of Messaging System Using Braille Code for Virtually Impaired Persons," International Journal of Advanced Research in Electrical,Electronics and Instrumentation Engineering, vol. 5, no. 7, pp. 5977-5984, July 2016.

6. K. Palanisamy and N. Dhamodharan, "Walking Stick with OPCFD System," GRD Journals- Global Research and Development Journal for Engineering,vol. 3, no. 1, pp. 1-5, December 2017.

7. Ahmed, AyeshaSultana, and P. Radha Rani. "A Study on Sensory Limitations amongElderly, in the SelectedOldage Homes of Hyderabad City." Available at SSRN 3094275 (2017).IMPACT: International Journal of Research in Applied, Natural and Social Sciences (IMPACT: IJRANSS) 5. 12, Dec 2017, 13-20

8. M. H. Mahadev and M. S. Prabhakar, "SMS Communication System for Blind People," International Journal for Research in Engineering Application \& Management (IJREAM), vol. 3, no. 2, pp. 6-10, Apr 2017.

9. R. Sarkar and D. R. Smita Das, "A low-cost Microelectromechanical Braille for blind people to communicate with blind or deaf-blind people through SMS subsystem," IEEE International Advance Computing Conference (IACC), pp. 1529-1532, 2013.

10. Hussein, Mustafa Rasool, and Hasanain Mohammed Ali Makki. "Neurological Assessment of Hemodialysis Patients A Single Center Study. International Journal of Medicine and Pharmaceutical Science (IJMPS) 8. 2, Apr 2018, 57-74

11. B. V. R. Chary and Santosh Kumar, "Rescue System for Visually Impaired Blind Persons," International Journal of Engineering Trends and Technology (IJETT), vol. 16, pp. 153-155, Oct 2014.

12. P. P. Chitte, S. A. Thombe and Y. A. Pimpalkar, "Braille To Text and Speech For Cecity Persons," International Journal of Research in Engineering and Technology, vol. 4, no. 1, pp. 263-268, Jan-2015.

13. D. Sreenivasan and S. Poonguzhali, "An Electronic Aid for Visually Impaired in Reading Printed Text," International Journal of Scientific \& Engineering Research, vol. 4, no. 5, pp. 198-203, May-2013.

14. Sandhu, Puneet, and Dazy Zarabi. "Self-Regulated Learning and Well-Being in Mainstream Classrooms: Focussing the Lens on Students with Learning Disability." International Journal of Educational Science and Research 8.1 (2018): 75-90.

15. R. B, Harini V and R. D. , "A Novel Approach As An Aid For Blind,Deaf And Dumb People," in International Conference on Sensing, Signal Processing and Security (ICSSS), 2017.

16. S. A. Mahesh, K..Raj Supriya, T. and M.V.S.S.N.K.Pushpa Latha, "Smart Assistive Shoes and Cane: Solemates for the Blind People," International Journal of Engineering Science and Computing, vol. 8, no. 4, pp. 16665-16672, April 2018.

17. M.Rajasenathipathi, M.Arthanari , "An Electronic Design Of A Low Cost Braille Handglove," International Journal of Advanced Computer Science and Applications (IJACSA), vol. 1, no. 3, pp. 52-57, September 2010.

18. I. Ulrich and Johann Borenstein, "The GuideCane-Applying Mobile Robot Technologies to Assist the Visually Impaired," Ieee Transactions On Systems, Man, And Cybernetics-Part A: Systems And Humans, vol. 31, no. 2, pp. 131-136, MARCH 2001 . 
19. T. amemiya, J. yamashita and k. h. , "Virtual Leading Blocks For The Deaf-Blind:A Real-Time Way-Finder by VerbalNonverbal Hybrid Interface and High Density RFID Tag Space," in Proceedings of the 2004 Virtual Reality (VR'04), Chicago, IL USA, March 2004. 